\title{
EL BICENTENARIO DE LA INDEPENDENCIA COMO COYUNTURA CRÍTICA DE CAMBIO EN CENTROAMÉRICA Y LA CONTRIBUCIÓN DE LOS SOCIOS PARA EL DESARROLLO: EL CASO DE ESPAÑA
}

\author{
THE BICENTENARY OF INDEPENDENCE AS A CRITICAL \\ JUNCTURE OF CHANGE IN CENTRAL AMERICA AND \\ THE CONTRIBUTION OF DEVELOPMENT PARTNERS: \\ THE CASE OF SPAIN
}

\author{
Pedro Caldentey del Pozo ${ }^{1}$ \\ ORCID: 0000-0001-5167-2446
}

\section{RESUMEN}

El bicentenario centroamericano coincide con una coyuntura de cambio en la región, alimentada por factores internos y globales. Tras cuarenta años de inspiración de las estrategias nacionales y regionales de desarrollo, el plan derivado de los Acuerdos de Esquipulas ha ofrecido ya todo lo que podía dar. $\mathrm{Ha}$ mejorado significativamente el bienestar de la región, pero ni ha roto la dependencia de los intereses particulares ni tiene respuesta a los problemas actuales, agravados por la crisis y la pandemia. El marco regional parece de nuevo el ámbito más adecuado para definir nuevos consensos para salir de la crisis y enfrentar el futuro. En la generación de estos consensos y en el fortalecimiento de lo regional tiene España una función que cumplir como socio destacado de la región.

Palabras clave: Centroamérica, desarrollo, Esquipulas, integración, regionalismo, SICA

\begin{abstract}
The Bicentenary of the Central America independence matches with a critical juncture in the region, fuelled by internal and global factors. After forty years of inspiring national and regional development strategies, the plan derived from the Esquipulas Agreements has already delivered all it could. It has significantly improved the region's welfare, but it has broken neither dependence on special interests nor has it find solutions to the structural problems of the region, worsened by the Great recession and the pandemic. The regional framework seems to be, once again, the most appropriate place to define new consensus to challenge the crisis and face the future. Spain is a key partner of Central America and has a role to play in generating consensus and strengthening the regional dimension.
\end{abstract}

Keywords: Central America, development, Esquipulas, regional integration, regionalism, SICA

1 Universidad Loyola Andalucía en Córdoba (España). Doctor en Ciencias Económicas y Empresariales. Director del Departamento de Economía e investigador principal del Instituto de Desarrollo. Correo electrónico: pcaldentey@uloyola.es 


\section{Introducción}

La celebración del bicentenario de la independencia de Centroamérica ha generado un momento muy relevante para la reflexión sobre el futuro de la región y que es muy oportuno para el debate académico. Los aniversarios son siempre una ocasión de fortalecimiento de la identidad, pero tienden a cierta retórica. Esta conmemoración parece adoptar un carácter diferencial porque coincide con un cambio de época que es global y que, en Centroamérica, se refuerza con variables propias.

Se trata de una coyuntura crítica (critical juncture) al estilo de Acemoglu y Robinson, es decir, "una confluencia de factores que trastorna el equilibrio económico o político existente en la sociedad (...), un arma de doble filo que puede provocar un giro decisivo en la trayectoria de un país" (o región, interpretamos). Se trata de un momento de cambio que, en la terminología de los autores, puede propiciar la progresiva desaparición de las instituciones extractivas, para dar paso a otras más inclusivas o todo lo contrario (Acemoglu y Robinson 2012: 127 y ss.).

La historia de la Centroamérica independiente tiene varios hitos importantes. Pero en la Centroamérica contemporánea, este momento es equiparable a los años de la posguerra mundial durante la década de 1950 o al período de los Acuerdos de Paz tras la crisis regional de los años ochenta. Son dos lapsos en los que coincide un cambio global de paradigma en las relaciones internacionales con un periodo de cambios políticos o económicos en los países centroamericanos.

Tras el final de la Segunda Guerra Mundial (IIGM), en 1945, con la creación de las Naciones Unidas y los acuerdos de Breton Woods, se construye un nuevo sistema de relaciones multilaterales que va a marcar el inicio de un largo período de expansión global, apoyado en un modelo de desarrollo con un enfoque de inspiración keynesiana. Este modelo facilita el desarrollo del Estado de bienestar en varios países del mundo con significativos avances en los Estados menos desarrollados.

Los países centroamericanos se plantean, en este entorno, la corrección de su modelo agroexportador, dejan atrás su dependencia de la economía de enclave y se suman al modelo de sustitución de importaciones, con el incentivo adicional de corregir los niveles de exclusión económica en sociedades sometidas en varios países por dictaduras militares. 
La crisis de los años ochenta y la expansión regional de los conflictos nacionales coincide de nuevo con dinámicas de cambio global y regional. Tras las crisis del petróleo, se produce una nueva renovación de los paradigmas económicos y ante la importancia de los desequilibrios macroeconómicos (la deuda es una expresión más extendida, incluso que la inflación en América latina), así se impone globalmente el enfoque neoliberal.

En Centroamérica lo hará mediante los programas de ajuste estructural y del llamado Consenso de Washington (Evans 1995, Williamson 2002). Centroamérica se enfrenta en esos años a la necesidad de frenar las guerras civiles y conflictos de la región que son la decantación de sus problemas estructurales (pobreza, autoritarismo, violencia) pero que están sublimados por la intervención externa de los bloques implicados en la Guerra Fría.

El resultado de estas variables deviene en los Acuerdos de Esquipulas que los países centroamericanos son capaces de firmar, al reducir la injerencia externa y con el apoyo del Grupo de Río, el Proceso de Contadora y la mediación de otros Estados. Los Acuerdos de Paz en la región responden a las variables endógenas que resuelven los conflictos en Nicaragua, El Salvador y Guatemala y su dimensión regional. Al mismo tiempo, conectan la propuesta de paz, democracia y desarrollo surgida de los acuerdos con el modelo neoliberal imperante en la sociedad global.

El entorno de los inicios de la segunda década del siglo XXI parece ser una nueva coyuntura crítica de cambio. La sociedad global está abrazando un nuevo paradigma de desarrollo todavía en definición. En el ámbito económico, las políticas fiscales y monetarias expansivas sugieren un movimiento pendular con respecto a las políticas neoliberales que promovían los equilibrios macroeconómicos por encima de otros objetivos y trataban de eludir la intervención en los mercados. El agotamiento del modelo neoliberal y sus soluciones a las crisis y la emergencia de nuevos problemas como la desigualdad o el cambio climático son los vectores de estos cambios. En la región, como se analizará, el modelo de desarrollo se ha ido desdibujando y perdiendo eficacia, mientras los países centroamericanos parecen presos de un proceso de des-democratización.

Así, este manuscrito se centra en dos focos de análisis. Por una parte, en la evolución del desarrollo de la Centroamérica contemporánea desde la perspectiva de un enfoque regional, con especial énfasis en el análisis de la coyuntura crítica que vive la región. Por otro lado, y en ese marco, se analizará la relación de Centroamérica y España durante las últimas décadas, dado su condición de socio prioritario de la región (junto a Estados Unidos, la Unión Europea y 
México) y que es uno de los socios que más importancia concede al enfoque regional en sus relaciones con Centroamérica.

Las coyunturas críticas de los años cincuenta y los ochenta tuvieron efectos positivos en el bienestar general y generaron avances en el desarrollo centroamericano, pero no consiguieron cambiar la naturaleza de las instituciones extractivas de la región. Este artículo explora si la coyuntura crítica asociada al bicentenario de la independencia puede ser la oportunidad de instaurar instituciones más inclusivas en Centroamérica. Además, examina el rol que un socio para el desarrollo como España, puede ejercer en torno a esa pretensión.

\section{Los grandes retos de la Centroamérica del bicentenario}

La región se presenta a esta nueva coyuntura crítica: cuarenta años después de los Acuerdos de Paz y del proceso de Esquipulas. El balance de sus resultados, decíamos en la introducción, es positivo pese a los altibajos de estas décadas. Se han producido cambios sensibles porque los acuerdos fueron capaces de viabilizar la solución de los conflictos y de propiciar varias décadas de paz y entendimiento entre los países. Propiciaron, también, el final de los gobiernos autoritarios en todos los países de la región y la apertura de procesos de democratización. Facilitaron, también, la puesta en marcha de estrategias de desarrollo que fomentaron una mejor inserción de las economías centroamericanas y una cierta reducción de la pobreza y mejora del bienestar en algunos sectores.

Los avances han sido sensibles pero insuficientes. Como han señalado Diego Sánchez Ancochea y Salvador Martí, los Acuerdos de Paz fueron también el marco de estrategias nacionales de desarrollo para los países centroamericanos que pudieron enfrentarse, con un marco común, a un escenario conformado por la violencia, asociada a los conflictos nacionales y a su regionalización; así como a los efectos de un modelo socioeconómico agroexportador, al servicio de las élites y, generador de exclusión y desigualdad (Sánchez Ancochea y Martí, 2014).

La paz del conflicto regional ha cedido frente a las raíces estructurales de la violencia asociada al narcotráfico y otras manifestaciones de violencia organizada. La región centroamericana se convirtió, hace años, en uno de los focos más violentos del mundo, especialmente en torno a la ruta migratoria hacia Estados Unidos y en los países del llamado Triángulo Norte (Honduras, Guatemala y El Salvador), una definición cargada de connotaciones negativas que seguro habría que descartar. 
La democracia que parecía consolidada, al menos en sus rasgos más formales (elecciones limpias y libres, separación de poderes), parece haber cedido también; de esta manera se puede afirmar que hay un grave riesgo de des-democratización en muchos de los países de la región. No se trata de un fenómeno exclusivo de Centroamérica y se puede enmarcar en la crisis de la democracia moderna (Levitsky y Ziblatt, 2018) que explica también algunos casos como la legislatura del presidente Trump en EE. UU., o los de algunos países de la Europea del Este en la UE, por no recurrir solo a los casos de Rusia o Bielorrusia.

En Nicaragua, el régimen de Daniel Ortega entró, a partir de la cruenta represión de las manifestaciones y protestas de abril de 2018, en una dinámica de represión que se multiplica con la cercanía de las elecciones de noviembre de 2021 y los numerosos casos de exilio forzado, encarcelamiento e inhabilitación de todos los candidatos electorales con voluntad de oposición, mediante leyes creadas ex profeso para ello y de difícil justificación jurídica.

El gobierno de Bukele había suscitado gran expectación en El Salvador al haber derrotado, con una gran contundencia, a los partidos tradicionales de la posguerra (ARENA y FSNL). Pero su mandato ha estado plagado de gestos autoritarios que han afectado, de forma sensible, la percepción de su proyecto político de renovación, en especial fuera del país, porque mantiene todavía altos niveles de popularidad interna.

El desgaste del presidente Hernández, en Honduras, es un síntoma de un deterioro democrático que viene desde el golpe de Estado al presidente Manuel Zelaya en el 2009, precisamente por su intención de aprobar la reelección mediante modificación constitucional, aunque más adelante fuera aprobada por una decisión de la Corte Suprema de Justicia que habilitó la reelección de Hernández, muy controvertida por las sospechas de manipulación de los resultados electorales. Además, la condena por narcotráfico de su hermano en EE. UU. salpica al presidente Hernández para el que se prevé un futuro judicial complejo.

Guatemala no ha recuperado la calma desde las grandes manifestaciones del año 2015, que acabaron con el procesamiento del expresidente Otto Pérez Molina y otros miembros de su gobierno. Ni la presidencia de su sucesor, Jimmy Morales, ni la del presidente Alejandro Giammatei han apaciguado los problemas del país ni las protestas ciudadanas que han vuelto a aparecer con intensidad en otros episodios. Los casos de corrupción entre la clase política y la difusa separación de poderes son una constante de la situación política en un país marcado por la existencia de élites empresariales muy reacias al cambio, por ejemplo, en la política fiscal. 
Antes del final de su mandato, el expresidente Morales consiguió la expulsión de facto o no renovación de la Comisión contra la impunidad en Guatemala (CICIG), que había destapado numerosos casos de corrupción gracias a la colaboración internacional con la justicia guatemalteca (expresidentes, empresarios, militares, jueces, jefes de policía, ministros, alcaldes y políticos de todos los partidos fueron encausados o encarcelados). Ese debate sigue abierto en medio de un marco de numerosos partidos y mayorías legislativas muy débiles.

Los países más al sur de la región se alejan de este panorama marcado por la crisis de la democracia. Costa Rica mantiene la estabilidad política pese a la aparición de fuerzas populistas con potencial desestabilizador y al debate que, desde hace algunos años, se ha planteado sobre la viabilidad del particular modelo económico y social que ha distinguido al país a partir de los años cincuenta. Por su parte, Panamá permanece también estable, después de los episodios de corrupción, aunque ha sido especialmente afectado por la pandemia y trata de reanimar su desigual economía en medio de las tensiones provocadas por su inclusión en la lista de paraísos fiscales de la Unión Europea. Mientras tanto, Belice y la República Dominicana, a pesar de ser países miembros del SICA, están alejados de la situación regional.

Si la transición de la guerra a la paz se ha visto complicada por la violencia del crimen organizado, y los avances democráticos parecen en retroceso, algo similar se podría afirmar sobre el desarrollo, el tercero de los principios de Esquipulas. Las mejoras de estas décadas no han sido suficientes para corregir los niveles de pobreza, desigualdad o de vulnerabilidad.

Tres documentos son especialmente valiosos y significativos para hacer balance de las décadas posteriores a Esquipulas. En primer lugar, Revoluciones sin cambios revolucionarios, una de las últimas obras de Edelberto Torres-Rivas (Torres-Rivas, 2011). En segundo lugar, la contribución que hacen los autores del Handbook of Central American Governance (Sánchez Ancochea y Marti, 2014). Ambos trabajos sostienen que los procesos de paz tuvieron éxito al romper una dinámica regional muy negativa y difícil, pero no han evitado la consolidación del modelo económico excluyente que sigue condicionado por los intereses de las élites. Torres-Rivas sintetizó muy bien varias décadas de la región afirmando que los procesos revolucionarios que desataron los conflictos no trajeron cambios revolucionarios en las estructuras políticas y económicas de la región. Sánchez-Ancochea y Martí (2014) hacen, también, especial hincapié en ello, con su idea de que los intereses de las élites siguen imponiéndose sobre los generales. 
El tercer documento es el último Informe sobre el Estado de la Región, una secuencia de informes que es la principal contribución al análisis con enfoque regional que existe en Centroamérica. Su análisis riguroso y persistente de los principales problemas de la región desde 1999 es una contribución extraordinaria en la que conviene destacar su adopción de una mirada regional, mucho menos frecuente de lo necesario, en las investigaciones sobre Centroamérica.

El sexto Informe sobre el Estado de la Región estudia ampliamente las dimensiones del desarrollo en Centroamérica. Presta especial atención a los retos a largo plazo, que identifica en torno al análisis espacial de los desastres naturales, la conflictividad ambiental y la evolución de la política institucional y propone análisis en profundidad en torno al empleo, la educación y formación, la dinámica territorial de la violencia y el apoyo a la democracia (Proyecto Estado de la Nación, 2021).

Los Informes del Estado de la Región ofrecen la posibilidad de estudiar la evolución de los problemas centroamericanos y la influencia del entorno global en ellos, pero intentarlo es un ejercicio que desborda las posibilidades de este artículo. Sin embargo, el Informe del Estado de la Región de 2021 propone tres grandes ideas fuerza como síntesis de sus investigaciones que ayudan a hacer un balance de los problemas de la Centroamérica contemporánea. La primera idea fuerza se refiere al retroceso que la pandemia ha provocado en los tímidos avances que la región había experimentado en los años 2015-2019 en materia de violencia, reducción de la pobreza o acceso a la educación. La debilidad institucional no ha podido frenar el impacto de esta pandemia que compromete en muchos aspectos el futuro inmediato de la región.

La segunda idea, pone de manifiesto las potentes señales de agotamiento político del impulso integracionista que generó logros tangibles de desarrollo humano tras su refundación con el SICA. Su agotamiento ha impedido que fuera, esta vez, un escudo frente a la crisis que ha provocado la pandemia. Y la tercera idea fuerza se centra en las identidades regionales que son claves para fortalecer el apoyo ciudadano a la integración sobre el que construir las respuestas que Centroamérica necesita.

Un reciente ejercicio de reflexión colectiva impulsado por la Fundación ETEA, Instituto de Desarrollo de la Universidad Loyola Andalucía, entre un grupo de cincuenta investigadores centroamericanos y centroamericanistas (Fundación ETEA 2021), proponía una lista de problemas críticos que deben estar en la base de cualquier replanteamiento de objetivos y de agendas para la región que ayuden a abordar el análisis sobre la Centroamérica contemporánea. El análisis de la región en esta coyuntura crítica se puede resumir en estas ocho claves 
que resultan agravadas por los efectos de la pandemia (Caldentey, Estepa, De la Torre 2021):

a) La democracia y el estado de Derecho están sometidos a riesgos sensibles y a retrocesos poco previsibles desde hace algunos años. Los ataques a la democracia y a la separación de poderes, la captura de los Estados para servir a intereses particulares, las debilidades en los procesos electorales, la poca garantía del respeto a derechos humanos fundamentales, entre ellos la libertad de expresión; la falta de imparcialidad en el sistema de justicia, la corrupción de las élites (económicas y políticas) o la penetración del crimen organizado son manifestaciones recientes de estos riesgos y retrocesos.

b) El Estado sigue sometido a importantes limitaciones en términos de capacidad y de eficacia, lo que compromete la calidad y extensión de servicios y necesidades básicas.

c) La crisis fiscal es una dimensión extraordinariamente importante en este debate: cargas tributarias bajas, alejadas de los principios de equidad vertical y horizontal y con tendencia a la reducción; gasto público insuficiente para garantizar derechos, propiciar la igualdad y apuntalar las bases de la democracia y del cumplimiento de los objetivos de desarrollo, nacionales e internacionales (ODS); poca transparencia y rendición de cuentas en contraste con amplios caminos abiertos a la corrupción que debilitan la legitimidad del poder público; $\mathrm{y}$, finalmente, una deuda pública creciente que, de mantenerse las tendencias actuales, será insostenible en los próximos años y obstaculizará cualquier proceso de desarrollo.

d) Los Estados no han desarrollado las capacidades e instrumentos necesarios para convertirse en mediadores efectivos de los intereses, aportando los equilibrios en la construcción del interés general. En ausencia de esa efectiva mediación, los intereses particulares de las élites económicas han tenido un peso mayor en el diseño y ejecución de las políticas públicas y en los niveles de fiscalidad, las cuales reflejan ese desequilibrio natural de acceso a la toma de decisiones. De igual forma, el liderazgo que ejercen las élites no ha sido ni eficaz ni suficiente para fomentar el crecimiento económico requerido para lograr un desarrollo inclusivo y la reducción de la pobreza.

e) La región sigue sometida a la presión de la violencia y del crimen organizado que se enraíza en sus vulnerabilidades, por su posición geográfica, la escasa presencia de los estados en partes de los territorios nacionales, la porosidad de las fronteras que facilita el tránsito ilegal de estupefacientes, pero sobre todo en la falta de oportunidades de desarrollo a base de 
actividades económicas legales y sostenibles. La violencia trastoca la vida cotidiana de amplios sectores de la población, que no puede desarrollar su vida con normalidad.

f) El modelo de desarrollo no es inclusivo y la pobreza y la desigualdad persisten. Ni las políticas públicas, ni la actividad privada, ni el desarrollo productivo generan inclusión. Los avances que se producen en la reducción de la pobreza y la desigualdad en épocas de crecimiento no son estructurales y retroceden en caso de crisis. La región sigue provocando que su gente vuelque sus posibilidades en la emigración, incluso en condiciones irregulares, lo que compromete que las remesas sean un factor sólido de cambio.

g) Se observa un agravamiento de las vulnerabilidades sociales y ambientales, tanto por la falta de asistencia y protección estatal a grupos en riesgo, como por la posición geográfica susceptible a fenómenos naturales que afectan con frecuencia la región. En el caso de la vulnerabilidad social, factores de oportunidad como la edad de la población, se contrarrestan con la falta de acceso a educación de calidad, la baja cobertura de servicios de salud, altas tasas de embarazo adolescente, violencia contra la niñez, la juventud y las mujeres, entre otros.

h) El sistema productivo no contribuye suficientemente al desarrollo. Por un lado, es altamente heterogéneo: coexisten industrias altamente productivas con una mayoría de baja productividad, lo que incide en bajos ingresos y alta concentración de los mismos. Por otro lado, el dinamismo del sector productivo no es suficiente para generar los empleos requeridos por una amplia población joven. Finalmente, se concentra en sectores tradicionales y de bajo valor agregado por lo que el componente importado de la producción es muy alto y concentrado en sectores de mayor valor. Por lo tanto, es importante incidir sobre los factores que determinan el crecimiento y cambiar los patrones del mismo para que este sea menos concentrador, más dinámico y más sostenible. Será necesario debatir sobre el crecimiento, la inversión, la estructura productiva y fiscal, las ocupaciones, el progreso técnico en los sectores económicos y la productividad laboral.

i) La inserción internacional de las economías de la región responde a un modelo que prima una inserción de bajo valor añadido en las CGV y la economía global. La economía mundial está mutando y el marco de la globalización está siendo sometido a cambios que no deben pillar desprevenidos a los agentes de la región. 
j) La región tiene un crecimiento vulnerable a los efectos de los desastres y al impacto del cambio climático. Sus herramientas de prevención y mitigación son insuficientes. El cambio climático amenaza regularmente con devastar los planes de futuro familiares y colectivos de los/las centroamericanos/as.

Se trata de un balance oscurecido porque se hace en la fase de agotamiento de un largo ciclo de desarrollo que se ve, además, agravado por los efectos de la pandemia. Se realiza, también, en un período marcado por las incertidumbres de la sociedad global que afectan, en específico, a los países más vulnerables. No obstante, conviene no olvidar que la región tiene grandes potencialidades sobre las que apoyar una nueva fase de desarrollo y que de las coyunturas críticas se puede salir reforzado con estrategias de medio y largo plazo. Podría haber escenarios propicios para cambios positivos para la región.

De los análisis que se presentan en este apartado parece obvio deducir la pertinencia de la dimensión regional del análisis sobre Centroamérica. Las investigaciones, impulsadas por los Informes del Estado de la Región o el ejercicio de reflexión impulsado por la Fundación ETEA, ofrecen un marco analítico sobre problemas que, aunque tienen manifestaciones diversas en cada país, derivan de las mismas raíces. Como Sánchez-Ancochea y Martí (2014), se cree que la ausencia o debilidad de los proyectos nacionales en los países centroamericanos forma parte del agotamiento de los principios inspiradores de todos ellos, derivados de los Acuerdos de Esquipulas y su aplicación.

\section{La integración regional ante los retos del bicentenario}

El análisis de la integración se hace pertinente y necesario si parte de que el enfoque regional es un instrumento útil para entender la región. Los Acuerdos de Paz incorporan como elemento funcional la reactivación del proceso de integración regional y los países centroamericanos reestructuraron el Mercado Común Centroamericano (MCCA) transformándolo, a través de nuevos protocolos, a los viejos tratados en el "Sistema de la Integración Centroamericana (SICA), un esquema multidimensional que definió un nuevo marco político y estratégico y amplió el entramado jurídico e institucional" (Caldentey, 2015: 178).

Las contribuciones del proceso del SICA en estas últimas décadas han sido variadas. Se pueden distinguir las siguientes etapas en su evolución en estos años: 
- 1986-1990: Proceso de paz y resolución de los conflictos en el marco de los acuerdos de Esquipulas I y II.

- 1990-1995: Renovación y reestructuración de la integración y desarrollo de la institucionalidad derivada de los nuevos protocolos y tratados.

- 1996-2001: Surgimiento de la propuesta estadounidense del Área de Libre Comercio de las Américas que induce un período de atonía en la integración, misma que dificulta la consolidación de la apuesta por la integración e interrumpe su desarrollo.

- 2002-2008: Dinamismo de la integración regional con el impulso de los Grupos Consultivos posteriores al huracán Mitch de 1998, 1999 y 2001, que dan lugar a la agenda para la trasformación y modernización de Centroamérica. La integración experimenta un impulso que se manifiesta en el crecimiento de sus instituciones y actividades, gracias al interés de la cooperación internacional por los proyectos y políticas regionales.

- 2009-2013: Incertidumbre en la integración provocada por la crisis institucional de Honduras, los episodios de tensión entre Nicaragua y Costa Rica por el río San Juan y los efectos de la Gran recesión global. La crisis no interrumpe la expansión de la integración y tras la incertidumbre inicial se produce una reactivación del proceso, en el que destaca la Conferencia Internacional de apoyo a la Estrategia de Seguridad de Centroamérica (ESCA).

- 2014-2021: El SICA entra en una nueva fase de atonía provocada por la pasividad de los estados miembros y la frustración ante los resultados de la Conferencia Internacional de apoyo a la ESCA y ante la falta de eficacia de los proyectos y políticas regionales. Ni siquiera la expectativa del bicentenario ni el nombramiento de Vinicio Cerezo como Secretario General del SICA, en el año 2017, modifican el funcionamiento de la integración cuya agenda pierde intensidad y protagonismo.

A pesar de lo anterior, es difícil sintetizar el estado de la integración regional en Centroamérica. La dimensión económica parece vivir un buen momento pese a que sus alcances se puedan percibir como limitados. La integración económica en Centroamérica ha demostrado mayor relevancia que en otros bloques del regionalismo latinoamericano. En el marco de la Unión Aduanera, el mercado intrarregional es el segundo destinatario de las exportaciones de la región detrás de Estados Unidos. Tras los años ochenta, la cuota intrarregional de 
exportaciones no deja de crecer y supera las cifras alcanzadas por el MCCA, consolidándose en torno al 30-35 \% y con algunas evidencias que apoyan el comportamiento anticíclico del comercio intrarregional. La evolución de las importaciones intrarregionales es también significativa, aunque inferior, en torno a $15 \%$ de las importaciones totales (Caldentey, 2021).

Centroamérica es, en 2021, una unión aduanera imperfecta formada por Guatemala, El Salvador, Honduras, Nicaragua, Costa Rica y Panamá (que está adoptando, de forma progresiva, el acervo legal asociado a la unión aduanera). República Dominicana y Belice no forman parte de ella. Existe un libre comercio intrarregional con algunas excepciones regionales y bilaterales. Además, se ha desarrollado una amplia normativa común sobre legislación aduanera como medidas de salvaguardia, origen de las mercancías, prácticas desleales, tránsito aduanero, medidas sanitarias y fitosanitarias, barreras no arancelarias, controversias comerciales, administración aduanera, transporte regional y otros asuntos (Caldentey, 2015).

Existe también un arancel externo común que cubre todo el universo arancelario (algo menos del $4 \%$ de los rubros que permanecen todavía desarmonizados por la sensibilidad de los intereses en torno a ellos). El principal problema de la unión aduanera está relacionado, sin embargo, con las incongruencias de los países miembros en su política comercial externa. Aunque la expectativa de las desgravaciones progresivas mitiga la gravedad de este problema, el arancel externo se enfrenta a negociaciones por separado que conceden preferencias arancelarias no comunitarias y que minoran en la práctica la eficacia de la Unión Aduanera y su legitimidad ante los productores y empresarios (Caldentey, 2015).

La integración económica centroamericana muestra también avances importantes en la facilitación comercial y la gestión integrada de fronteras; y cuenta con un marco intersectorial de instrumentos de política regional que tiene el apoyo de actores regionales como el BCIE y de socios externos con capacidad de apoyarlos en materia técnica o financiera.

Estas tendencias refuerzan una percepción positiva de la evolución de un mercado regional que es valioso y relevante para los agentes económicos, lo que en otros períodos no resultaba tan evidente. La integración económica centroamericana parece haber "promovido la competitividad de algunos sectores ligados al comercio exterior y la apertura de las economías latinoamericanas. Pero su enfoque resulta insuficiente para promover la distribución de sus efectos positivos y el desarrollo de las fuentes internas de crecimiento" (Caldentey, 2015: 187) y una estructura productiva competitiva e inclusiva que puede ofrecer 
alternativas de desarrollo a los países centroamericanos y adaptarse adecuadamente a los escenarios de futuro que la región va a afrontar.

En el ámbito más político de la integración regional, el SICA se ha dotado desde el año 2005 de un rico y heterogéneo conjunto de instrumentos de política regional. El conjunto de instrumentos tiene mucho valor, pese a la utilidad cuestionable de varios de ellos, y ha sido fruto del ejercicio de elaboración, con participación de socios extrarregionales y algunos procesos de consulta muy interesantes. La Política Regional MIPYME (2019), la Política Marco Regional de Movilidad y Logística Centroamericana de 2017, la Política Centroamericana de Gestión Integral de Riesgo de Desastres de 2017, la Estrategia Regional de Articulación Productiva MIPYME (2017), la Política Regional de Salud del SICA 2015-2022, la Política de Integración de Pesca y Acuicultura 2015-2025, la Política Regional de Igualdad y Equidad de Género del SICA o la Estrategia de Seguridad de Centroamérica (ESCA) de 2011, por citar algunas de ellas.

Sus resultados son, no obstante, limitados en términos de eficacia. Y ese es uno de los grandes debates de la integración. Sin olvidar el carácter complementario de lo regional, el reto es cómo hacer eficaces las intervenciones y las políticas regionales. Hay ejemplos concretos de instrumentos útiles e incluso tangibles más allá de la integración económica, por ejemplo, en torno a la prevención de desastres, o la atracción de la cooperación internacional, así como la compra conjunta de medicamentos o las políticas de promoción de la mipyme y el emprendimiento. Sin embargo, son resultados insuficientes para generar los incentivos necesarios para que los países miembros confíen en que la integración es un juego de suma positiva que puede ser rentable para todos a medio plazo.

Lo señala así el sexto Informe del Estado de la Región, a partir de las evidencias que aporta su capítulo 3 sobre las tendencias del proceso de integración regional, analizando la distancia entre las potencialidades y los resultados del SICA $\mathrm{y}$ apuntando algunas de las dificultades que explican los problemas de eficacia y compromisos asociados al sistema, en un debate que excede las posibilidades de este artículo:

Además de las asimetrías en capacidades y resultados, este Informe proporciona evidencia sobre la acumulación de señales sobre el agotamiento político del impulso integracionista inaugurado a fines del siglo pasado. Las diferentes naciones comparten recursos naturales e infraestructura, bienes públicos que podrían ser gestionados de manera conjunta para garantizar su adecuada protección, uso sostenible y mantenimiento oportuno. 
Centroamérica cuenta con veintitrés cuencas compartidas que representan el $37 \%$ del territorio de la región y posee más de un millón de $\mathrm{km}^{2}$ de mar territorial (el doble de su superficie continental), así como ecosistemas marinos y terrestres que trascienden las fronteras territoriales entre las naciones. (...). Si bien la voluntad expresada en esos instrumentos fundacionales del proceso de integración regional partió del reconocimiento de recursos e intereses compartidos entre los países, la implementación a nivel nacional de los compromisos suscritos en el ámbito regional es débil en muchas áreas. Los Estados nacionales son los socios principales del proceso de integración, y tienen la obligación de dar direccionalidad a este proceso y garantizar las condiciones políticas y materiales para la "nacionalización" de los acuerdos y compromisos suscritos en el espacio regional.

La falta de voluntad política agudiza los problemas endémicos del diseño institucional y la operación del SICA e impide su consolidación como plataforma para la aplicación de políticas públicas en temas de interés común para los países miembros. (Estado de la Región, 2021: 59-60)

En el marco de los problemas de Centroamérica, de esta coyuntura crítica en que se encuentra la región y del cambio de ciclo global que la enmarca, la integración es un ámbito imperfecto que no ha conseguido fructificar pese a ser el proceso de integración más dinámico de Latinoamérica. Pero dada la naturaleza y tamaño de sus estados miembros, está llamada a ser una fuente de soluciones tanto para definir estrategias de futuro, como para implementarlas.

\section{España ante los grandes retos de la Centroamérica contemporánea}

Se han analizado los problemas de la región y el enfoque regional que permite abordarlos. El alcance de este artículo es limitado, pero otra posible perspectiva sería la de los actores. El comportamiento e intereses de las élites centroamericanas, los partidos y movimientos políticos, la juventud, pueblos indígenas o movimientos sociales son variables de análisis relevantes. Sin duda, hablando de actores, entender la región exige estudiar el rol de actores externos como los Estados Unidos, la Unión Europea, España, China o los organismos internacionales y otros actores de la cooperación internacional.

El análisis del caso español puede ser interesante desde tres ángulos: Primero, por tratarse del antecedente colonial del que los países centroamericanos se independizaron en 1821. Segundo, este país es uno de los socios más importantes de la región y seguramente del más comprometido con su dimensión 
regional junto a la UE. Tercero, porque para España, Centroamérica ha sido un ámbito de cooperación muy significativo y porque también lo ha sido en otras facetas de la política exterior española e, incluso, de la internacionalización de sus empresas.

"La experiencia en Centroamérica de la cooperación española ha sido profunda y de largo recorrido. Han estado presentes en la región todos sus actores y todos sus instrumentos han tenido una aplicación intensa y muchas veces pionera" (AECID, 2015: 187). Centroamérica es la región del mundo que explica mejor la evolución y madurez de la política exterior española. Su dimensión regional constituye, por otra parte, su primera aproximación a la región con el primer programa regional de la cooperación de España en Centroamérica que nació en la primera mitad de los ochenta y es, incluso, anterior a los programas bilaterales que tanto desarrollo han tenido después (Ramos Rollón, 2021).

De acuerdo con la AECID (2015: 189) "La cooperación con Centroamérica explica también el origen de buena parte de la cooperación no gubernamental. Tras la primera generación de ONGD de carácter religioso, en los años 80 surge en España una nueva generación de organizaciones derivadas de los movimientos de solidaridad con Nicaragua, El Salvador y Guatemala, en el marco de los conflictos centroamericanos".

De esta forma, Centroamérica fue protagonista en el desarrollo de la cooperación descentralizada española. "Todos (sic) las autonomías, los ayuntamientos, diputaciones y fondo municipales de solidaridad, han estado o están en Centroamérica. La cooperación española ha estado presente en Centroamérica con todos sus actores y todos sus instrumentos. Todos los instrumentos bilaterales o multilaterales han sido intensamente aplicados en Centroamérica" (AECID, 2015: 189).

La presencia de AECID en la región inició con el Plan Integral de Cooperación con Centroamérica en 1984, con el cual se abrieron las primeras oficinas de cooperación técnica (lo que hoy se conoce como Agencia Española de Cooperación Internacional al Desarrollo). En esos años, la región estaba inmersa en sus conflictos políticos y militares y, en ese contexto, los mandatarios del Grupo de Contadora (México, Venezuela, Colombia y Panamá) emitieron, en julio de 1983, el Acta de Contadora para la Paz y la Cooperación en Centroamérica. "El Grupo de Contadora hizo también un llamamiento a los países desarrollados para contribuir a reducir los rezagos de la región que estaban en la base de los conflictos. Fue una solución latinoamericana, libre de injerencias de terceros, que se transformaría después en el Grupo de Río y que daría paso a las reuniones de Esquipulas I y II y a su contribución al final de los conflictos y a la reactivación de la integración" (AECID, 2015: 190). 
La diplomacia española participó activamente en los esfuerzos impulsados desde Contadora y Esquipulas. Los gobiernos de Felipe González (1982-1993) fueron parte de los esfuerzos internacionales de mediación y cooperación. La diplomacia española actuó también con intensidad en los Acuerdos de Paz de Nicaragua, El Salvador y Guatemala, promoviendo el diálogo y facilitando plataformas para el diálogo en cada uno de esos conflictos nacionales. Sin descartar la acción estadounidense, España fue, con México y otros socios de la región, un apoyo imprescindible en los esfuerzos centroamericanos por alcanzar la paz.

El impulso del Plan integral de 1984 dio paso a la cooperación bilateral que ha sido intensa y continuada desde entonces. Centroamérica ha sido y es hoy, una región prioritaria de intervención en el Plan Director de la AECID, que contempla en la región planes de cooperación con cinco países de asociación de renta media (El Salvador, Guatemala, Honduras, Nicaragua y República Dominicana) y tres países de cooperación avanzada (Panamá, Costa Rica y México).

La cooperación española con Centroamérica se ha ido adaptando a las necesidades de los países de la región y ha cubierto un número elevado de asuntos, aunque destacan todos aquellos relacionados con el fortalecimiento institucional, la cooperación técnica y la reforma del Estado, en cuya implementación ha sido también pieza importante el Centro de Formación de la Cooperación Española en Antigua Guatemala.

Otras áreas que destacan en la cooperación bilateral española es el apoyo a los programas de igualdad de género o la actuación en los entornos rurales. De esta manera, la cooperación española es una de las más importantes en términos financieros en Centroamérica, junto a la UE y a la de Estados Unidos.

Sin embargo, la importancia de la cooperación española no reside tanto en criterios cuantitativos, sino cualitativos. Sin hacer un balance exhaustivo de éxitos o fracasos por área, España ha jugado el rol de promover políticas y reformas que sin su intervención hubiesen encontrado dificultades para prosperar entre las limitaciones institucionales y presupuestarias de los gobiernos de la región. Es una aportación muy valiosa en una región caracterizada por la dificultad de imponer el interés general sobre los particulares. La cooperación española cuenta, además, con programas sectoriales o de ámbito latinoamericano y global (algunos en asociación con otros socios y agencias), y todos ellos desarrollan actividad intensa en Centroamérica. El Fondo del Agua o Eurosocial son dos instrumentos recientes de este tipo.

Centrando el análisis en la cooperación regional, España ha concedido un elevado protagonismo en su política exterior en América Latina a los organismos 
regionales y a los procesos de integración regional como motor de desarrollo (Ramos Rollón, 2021) y ha puesto en marcha programas de cooperación con el SICA, la Comunidad Andina, la CARICOM y Mercosur. Entre todos ellos, destaca por su volumen y profundidad, el apoyo al SICA. La cooperación regional no se reduce a la cooperación con procesos subregionales de integración. Algunos organismos y programas multilaterales reciben también atención preferente. Merece la pena señalar, en especial, el apoyo de España a la SEGIB, como dimensión regional de cooperación y diálogo con la región. La cooperación iberoamericana, más allá de su promoción de la cooperación triangular, es una oportunidad para que la región promueva sus intereses de manera colectiva.

Tras el Programa Integral de Cooperación, de naturaleza regional pero que dio lugar a la apertura de los importantes programas de cooperación subsiguientes, los grupos consultivos posteriores a Mitch, principalmente el celebrado en Madrid el año 2001, dieron un nuevo impulso al enfoque regional con la creación del Programa de Cooperación Regional con Centroamérica (PCRC), presentado a los países centroamericanos en la XII Cumbre Iberoamericana de Jefes de Estado y de Gobierno, en noviembre de 2002, en la República Dominicana. En el año 2004 se realizó una revisión del Programa de Cooperación Regional con Centroamérica con el objetivo de generar un salto cualitativo en sus alcances y presupuestos.

\section{Según la AECID (2015: 194):}

El programa de cooperación regional tenía como objetivo general la mejora del diseño y ejecución en la región de políticas públicas encaminadas hacia la obtención de un mayor desarrollo humano y una mejora de la eficacia en la lucha contra la pobreza. Su objetivo específico fue la promoción de espacios institucionales para la convergencia, coordinación y armonización de actores y políticas públicas de Centroamérica, en áreas clave para el desarrollo y la integración regional.

En el 2006 se produce un cambio de instrumento tras la firma del Memorando de Entendimiento entre el Ministerio de Asuntos Exteriores y Cooperación de España y el SICA para el establecimiento del Fondo España-SICA, que se puso en marcha en el año 2007 en una primera fase 2007-2009, a la que han seguido el Fondo España-SICA II (2010-2013), el Fondo España-SICA III (2014-2017) y el Fondo España-SICA IV (2018-2021), hoy vigente.

Más allá de los sectores y ejes de trabajo del SICA que el Fondo España-SICA ha apoyado, su relevancia tiene que ver más con su naturaleza como instrumento de eficacia de la ayuda. "El Fondo España-SICA traslada la responsabilidad de la ejecución a las instituciones del Sistema de la Integración y hace una 
apuesta por la eficacia de la ayuda, especialmente en la apropiación y el alineamiento con las agendas regionales de desarrollo y los sistemas y procedimientos de gestión y ejecución del SICA" (AECID, 2015: 201). La clave del Fondo es apoyar a las instituciones y a los países miembros del SICA respecto a estrategias y agendas estratégicas endógenas, así como la implementación gradual de normativas y procedimientos de gestión y seguimiento en las instituciones del SICA con el propósito de fortalecerlas (AECID, 2015).

Se considera que las evaluaciones del Fondo han hecho aportes valiosos debido a su flexibilidad y capacidad de adaptación, así como su elevado nivel de alineamiento y apropiación, convirtiéndolo en instrumento idóneo y versátil para la agenda del SICA. No obstante, el Fondo no es ajeno al estado de la integración y su evolución más reciente se contagia de la atonía del proceso. La cooperación internacional es también impaciente en los procesos y tiene pocos estímulos para esfuerzos de largo plazo sometidos a altibajos, aunque la apuesta española por la integración centroamericana es evidente.

Sin duda, la debilidad reciente de la cooperación española tras la gran recesión, pendiente de una reforma y modernización siempre aplazada (Olivié y Pérez, 2016), es un factor influyente en la evolución de la cooperación bilateral y regional con Centroamérica. La limitación del presupuesto español de cooperación internacional ha sobredimensionado la importancia que la cooperación española presta hoy a la cooperación delegada de la Unión Europea.

Cualquiera que sea la evolución de la cooperación española tras su reforma, no es probable que la importancia de América Latina en la política exterior española (y, por tanto, de Centroamérica) vaya a reducirse. Pese a todos los inconvenientes que rodean esa relación, el nexo de los agentes económicos, sociales y culturales es tan intenso que compensa las variables más políticas.

Si España quiere ser un país nodal en las relaciones internacionales, debe potenciar y revisar su relación con América Latina, dejando atrás un modelo de relaciones basadas en el legado civilizatorio (Malamud, Olivié y Escribano 2020). De tal forma, que la conmemoración de los bicentenarios parece un momento idóneo para celebrar esa estrecha relación más en torno a los proyectos de futuro que respecto a los lazos pretéritos.

El compromiso de España con Centroamérica parece incuestionable. La relación entre ambos, en todo caso, va más allá de la cooperación. Del enfoque regional de esta relación, emergen dos características fundamentales. Primero, la condición de España como portavoz y mediador de los intereses centroamericanos ante la Unión Europea y los foros multilaterales, los Estados Unidos y 
ante el mundo. Un rol que puede ejercer dada su capacidad de entender los intereses comunes de la región, expresados en su proceso de integración. Segundo, la contribución que España puede hacer en todos los ámbitos de su relación de Centroamérica (cooperación, diplomática, política, empresarial, no gubernamental), para promover instituciones inclusivas y fomentar la capacidad de los intereses generales sobre los particulares o de las élites extractivas de la región.

En junio de 2021 se celebró una Cumbre España-SICA que fue la primera reunión presencial de los Presidentes centroamericanos y la primera visita oficial de un presidente del gobierno a Costa Rica tras la pandemia. La cumbre se centró, primero, en el abordaje de la recuperación económica sostenible, verde e inclusiva y en la contribución de la cooperación regional de España con el SICA. Las migraciones, el cambio climático, la transformación tecnológica, la modernización del SICA y la recuperación de los efectos de la pandemia son temas que deben articular las nuevas agendas. Parece claro, por tanto, que, como el SICA en su conjunto, la cooperación regional española necesita una visión y un propósito para enfrentar los retos de la región y que ayude a renovar sus instrumentos.

\section{Conclusiones: coyuntura crítica de cambio en Centroamérica}

La hipótesis de que Centroamérica vive un cambio de época, una coyuntura crítica de cambio, es compartida de forma amplia, pero la región está lejos de encontrar la manera de transitar ese cambio. El pensamiento económico dominante de las décadas previas "ha centrado el debate en aspectos macroeconómicos e instrumentales, en la estabilidad y en la apertura como marco para el desarrollo. Dejó en segundo plano algunos ámbitos de intervención sectorial de carácter estratégico como el de la agricultura" (Caldentey, 2015: 192) o la innovación.

El sector privado centroamericano enfoca sus esfuerzos en algunas áreas donde encuentra incentivos a corto plazo (energías renovables, turismo) como ha ocurrido en otras épocas en sectores como el financiero, hostelería o distribución comercial. Esta estrategia no se ha mostrado eficiente para responder al interés común. En Centroamérica no se cumplieron tampoco las expectativas sobre crecimiento y trickle down. No se ha producido un incremento suficiente de la inversión doméstica porque los sectores más prometedores de las economías centroamericanas fueron adquiridos por la inversión extranjera, la cual pareciera que no ha generado inversiones derivadas, articulación sectorial; o bien, un mejor posicionamiento de la región en las cadenas globales de valor. Los problemas estructurales que la región arrastra desde su independencia y sus manifestaciones más recientes necesitan nuevos enfoques y soluciones. 
La coyuntura crítica de cambio tiene, otra vez, naturaleza regional. Aunque los problemas tienen características propias por país, responden a tendencias y variables comunes ya sea a nivel regional o global. Después de la IIGM, la región canalizó sus propuestas a través del MCCA y la sustitución de importaciones.

Tras los conflictos de los ochenta, Esquipulas ofreció un marco inspirador para nuevos objetivos y estrategias a través del SICA y la propuesta de regionalismo abierto. Posterior al huracán Mitch, la integración se activó con una nueva y amplia agenda que renovó la derivada de los Acuerdos de Esquipulas. La combinación de la pandemia y la Gran Recesión ha puesto al mundo y a Centroamérica en el límite de una nueva época y la región debe enfrentarse a ella con nuevas respuestas.

Doscientos años después de la independencia, Centroamérica tiene la oportunidad de reinventarse y conseguir que esta coyuntura de cambio la lleve a un marco de instituciones inclusivas que garantice un bienestar suficiente para todos sus ciudadanos y ciudadanas. La región ha sido testigo, más pasivo que activo, de iniciativas como la propuesta Biden-Harris para el triángulo Norte o del Plan de Desarrollo Integral El Salvador-Guatemala-Honduras-México que parecen algo desinflados, aunque llegaron a suscitar, incluso, la metáfora del Plan Marshall.

Un plan centroamericano, liderado desde la propia región parece una mejor opción. El Bicentenario de la Independencia se presentaba antes de la pandemia como la excusa para definir una nueva estrategia de futuro o un Esquipulas III que inspirara el desarrollo para el periodo 2021-2030 o 2021-2050. En torno a la Secretaría General y las instituciones del SICA se generaron varias iniciativas de propuestas de futuro que resume bien la Carta sobre el porvenir de Centroamérica de Vinicio Cerezo (Cerezo, 2020).

Así, la carta está llena de sugerencias interesantes, pero le falla el método, porque la formulación de las soluciones no es tan relevante como el diálogo que se genera en torno a ellas. Como suele pasar, la grandilocuencia de los objetivos se ve frenada por las demandas concretas de los instrumentos. El cómo es tan o más importante como el qué. ¿Cómo se generan consensos para que sean aceptados por todos e inspiradores? ¿Cómo se articulan las propuestas y los intereses, cómo se implementarán, con qué instrumentos y financiación?

El objetivo es doble: poner en marcha un proceso de diálogo y formular una agenda común factible y contenida que puede ofrecer resultados tangibles y ser un eficaz complemento a las estrategias nacionales o multilaterales. Sin duda, los liderazgos nacionales de todos los países centroamericanos, públicos 
y privados, son hoy más un obstáculo que un elemento a favor. La crisis de la institucionalidad, la re-emergencia del autoritarismo y la des-democratización juegan en contra de un proceso que exige consenso y mirada de largo plazo. Pero la incertidumbre es un rasgo común a todas las coyunturas de cambio. Es, en estos casos, que los dilemas se resuelven a favor o en contra de lo común, de las instituciones inclusivas.

Es ahí donde los socios para el desarrollo deben jugar un rol decisivo. No tanto como financiadores sino como promotores del diálogo político y de la generación de consensos. Crear incentivos para que los gobiernos centroamericanos se comprometan con el diálogo y las soluciones conjuntas es una función necesaria y urgente.

El nexo de España con el bicentenario debe ser un estímulo para que ejerza un rol activo como socio de la región. Primero, al animar los consensos o el método para conseguirlos entre los gobiernos centroamericanos, que aprovechen la institucionalidad y recursos del SICA, ya probados en épocas de conflicto. Segundo, al animar a la comunidad internacional a apoyar plataformas conjuntas de apoyo político y cooperación con Centroamérica en la pospandemia. Y tercero, al revisar sus instrumentos de cooperación con Centroamérica para que sean eficaces en la resolución de los retos de la Centroamérica de hoy, sin miedo a forzar los cambios y reformas que frenan el progreso y la equidad.

La integración centroamericana se enfrenta en el bicentenario a la necesidad simultánea de dar un paso adelante y de modernizar su funcionamiento. Los países miembros del SICA deben demostrar que se apropian del proceso de integración y lo empujan forma efectiva, para que exista una articulación real entre los intereses nacionales y regional, al dejar de esconderse detrás del argumento de la ineficacia de los órganos e instituciones que ellos lideran y forman.

Será importante discutir qué ámbitos del desarrollo centroamericano tienen una dimensión regional que hace necesaria la integración para consensuar y definir cuáles deben ser los ejes estratégicos de un plan de desarrollo a largo plazo factible y eficaz. Así, el Bicentenario reúne muchas condiciones para animar este proceso y, como en otros momentos, encontrar de forma conjunta salidas a la actual encrucijada centroamericana. 


\section{Referencias}

Acemoglu, D. y Robinson A. (2012). ¿Por qué fracasan los países? Ediciones Deusto.

Acuña Ortega, V. H. (editor). (1993). Historia general de Centroamérica, Volumen IV, Las Repúblicas agroexportadoras, Sociedad Estatal V CentenarioFLACSO, España.

AECID. (2015). 25 años cooperando con América Latina y el Caribe. https:// bibliotecadigital.aecid.es/bibliodig/i18n/catalogo_imagenes/grupo. cmd?path $=1010272$

Bulmer-Thomas, V. (1994). The Economic history of Latin America since independence, Cambrigde University Press, United States of America.

Caldentey del Pozo, P. (2015). Desarrollo económico en Centroamérica: vigencia y revisión de los acuerdos de Esquipulas. Icade. Revista De La Facultad De Derecho, (96), 169-199. https://doi.org/10.14422/icade.i96.y2015.007

Caldentey, P. (2021). Sesenta años de integración económica en Centroamérica: avances y retos. BCIE/SIECA/CMCA. Centroamérica.

Caldentey, P.; Estepa, L. y De la Torre, J. (2021). Central America at the Crossroads: The End of Esquipulas and the Search for a New Consensus. Policy Brief 2021-5. UNU Institute on Comparative Regional Integration Studies. https:// cris.unu.edu/Central $\% 20$ America $\% 20$ at $\% 20$ Crossroads $\% 20$ Covid $\% 20$ 19\%20Coronavirus

Cerezo, V. (2020). Carta por el futuro de la integración centroamericana. Secretaría General del SICA. El Salvador. Disponible en https:/www.sica.int/ integracion/2020/carta

Evans, T. (1995). La transformación neoliberal del sector público. Ajuste estructural y sector público en Centroamérica y el Caribe, Latino Editores, Nicaragua.

Fundación ETEA. (2021). Informe de sistematización y conclusiones del Seminario Determinantes del desarrollo de Centroamérica en el marco del proceso de integración regional y del Acuerdo de Asociación con la UE. https://fundacionetea.org/2021/04/05/seminario-determinantes-del-desarrollo-de-centroamerica-en-el-marco-del-proceso-de-integracion-regional-y-del-acuerdode-asociacion-con-la-ue/.

Levitsky, S., y Ziblatt, D. (2018). Cómo mueren las democracias. Editorial Ariel. España. 
Malamud, C., Olivié, I. y Escribano, Gonzalo (2020). Las relaciones España-América Latina en tiempos del Covid-19. Informe 2, septiembre 2020. Real Instituto Elcano.

Martínez, P., J. (editor). (2019). Logros y desafíos de la integración centroamericana. Los aportes de la CEPAL. CEPAL: Santiago de Chile.

Olivié, I. y Pérez, I. (2016). Catorce dilemas de la cooperación española en la nueva legislatura, $A R I$, n. $^{\text {o } 39, ~ M a d r i d, ~ R e a l ~ I n s t i t u t o ~ E l c a n o . ~ D i s p o n i b l e ~ e n: ~ h t t p: / / ~}$ www.realinstitutoelcano.org/wps/portal/rielcano_es/contenido?WCM GLOBAL_CONTEXT=/elcano/elcano_es/zonas_es/ari39-2016-olivie-perez-catorce-dilemas-de-la-cooperacion-espanola-en-la-nueva-legislatura

Pérez B., H. (1993). Historia general de Centroamérica, Volumen III: De la ilustración al liberalismo, Sociedad estatal V centenario-FLACSO, España, 292 págs.

Pinto S., J. (1993). Historia general de Centroamérica. Volumen II: El régimen colonial (1524-1750), Sociedad estatal V centenario-FLACSO, España, 383 págs.

Programa Estado de la Nación (2021). Sexto Informe sobre el Estado de la Región 2021. CONARE - PEN, 2021. San José, Costa Rica https://estadonacion.or.cr/ informe/?id=332ae9fc-d7c0-4886-a8cd-b67ea5f0ac38

Ramos R., Marisa (2021). La cooperación española en América Latina ¿Un cambio de ciclo? Documentos de trabajo 51/2021. Fundación Carolina. España

Sánchez-Ancochea, D. y Martí, S. (2014). “Central America's triple transition and the persistent power of the elite”, pp. 4-22, en Sanchez-Ancochea, D. y Martí, S. (2014), Handbook of Central Americana Governance. Routledge. UK.

Torres-Rivas, E. (2011). Revoluciones sin cambios revolucionarios. Guatemala: $\mathrm{F} \& \mathrm{G}$ editores.

Williamson, J. (2002). Did the Washington Consensus Fail? Outline of speech at the Center for Strategic \& International Studies Washington, DC. November 6, 2002. 
